Utah State University

DigitalCommons@USU

$1-1-1982$

\title{
In-Situ Measurements of Wave Electric Fields in the Equatorial Electrojet
}

\author{
R. F. Pfaff \\ M. C. Kelley \\ B. G. Fejer \\ N. C. Maynard \\ K. D. Baker
}

Follow this and additional works at: https://digitalcommons.usu.edu/sdl_pubs

\section{Recommended Citation}

Pfaff, R. F.; Kelley, M. C.; Fejer, B. G.; Maynard, N. C.; and Baker, K. D., "In-Situ Measurements of Wave Electric Fields in the Equatorial Electrojet" (1982). Space Dynamics Lab Publications. Paper 160.

https://digitalcommons.usu.edu/sdl_pubs/160

This Article is brought to you for free and open access by the Space Dynamics Lab at DigitalCommons@USU. It has been accepted for inclusion in Space Dynamics Lab Publications by an authorized administrator of DigitalCommons@USU. For more information, please contact digitalcommons@usu.edu.

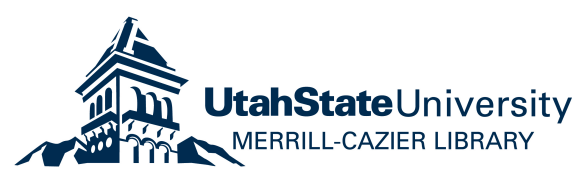




$$
\text { R. F. Pfaff1, M. C. Relley1, B. G. Fejer1, N. C. Maynard2, K. D. Baker3 }
$$

1. School of Electrical Engineering, Cornell University, Ithaca, NY 14853

2. Lab. for Extraterr. Physics, Goddard Space Flight Center, Greenbelt MD 20771

3. Utah State University, Logan, UT 84322

Abstract. Electric field wave measurements have been performed on two sounding rockets in the equatorial ionosphere. During a daytime flight from Chilca, Peru, intense electrostatic waves were detected on the upward directed electron density gradient. During a nighttime rlight from Kwajalein Atoll, similar waves were detected on a downward directed gradient. These results are in agreement with a gradient drift instability explanation of the generation of the waves. The wave amplitudes were as high as 5 mV/m implying perturbation drifts comparable to the driving drift velocities. Power spectra from the turbulent region show a peak at long wavelengths, followed by a nearly flat spectral region before breaking into a power law form with negative index of $3.6-3.7$ for $\lambda \leq 30 \mathrm{~m}$. Similarities between the spectra of the two flights suggest that the fundamental processes of the instabilities are the same in the day and nighttime conditions. The rocket data are consistent with radar results presented in a companion paper which show coherent, kilometer scale waves present in the electrojet.

\section{Introduction}

Electrostatic turbulence in the equatorial electrojet has been studied extensively for more than two decades using radar techniques and for more than one decade with rocket density probes (see review by Fejer and Kelley, [1980]). Both of these methods detect the density fluctuation component of the electrostatic waves in the electrojet. In this paper we describe the first rocket observations of the $\delta \mathrm{E}$ component of the unstable waves in the equatorial zone.

We present data from two rocket flights, one flown from the rocket range at Chilca, Peru (magnetic dip $=0.50$ ) and one flown from the Island of Kwajalein (magnet1c dip $=90$ ) in the South Pacific. In the first case, the rocket was launched when the electrojet was strong, at 11:07 local time $(16: 07$ U.T.), on June 7,1975 . At Kwajalein, the data were obtained during nightime conditions with a lift-off time of $10: 40 \mathrm{U} . \mathrm{T}$. on August 8, 1978, which corresponds to a local solar time of 21:40. The electric fleld detector flown from Peru utilized long cylindrical sensors (6.05 m tip-tc-t1p with $61 \mathrm{~cm}$ exposed) similar to the instrument described by Aggson [1969]. The Kwajalein data were obtalned using spherical sensors on the ends of a $3 \mathrm{~m}$ tip-to-tip boom system as described by Fahleson [1967]. In both cases the telemetry included separate channels for dc/low- and ac/high-frequency data.

Copyright 1982 by the American Geophysical Union.

Paper number $2 \mathrm{~L} 0691$.

0094-8276/82/002L-0691\$3.00
A companion paper by Kudek1 et al. [1982], hereafter referred to as paper 1, describes measurements made at the Jicamarca Radar Observatory using an interferometric technique. These show coherent, large amplitude, kilometer-scale waves in the electrojet, observations that are strongly supported by the data presented here. In addition, the data sets in this paper show perturbed wave electric fields that are comparable to the predicted ambient electric field, and yield wave number spectra over more than three decades in spatial scale and six decades in power.

\section{Data Presentation}

Raw electric field data from the downleg of each flight are presented in Fig. 1. In the daytime Peruvian experiment (1a), the data are taken from a dipole oriented $45^{\circ}$ to the spin axis, and correspond to a region between 115 and $92 \mathrm{~km}$. The data from the nighttime Kwajalein experiment (1b) are taken from a dipole oriented perpendicular to the spin plane, and cover a smaller altitude region (99-92 km). For each flight, the smooth, slowly varying sine wave, primarily due to the $\underline{V} \times \underline{B}$ electric field generated by the rocket motion across the magnetic field, is interrupted by fluctuations about the instantaneous value of the spin modulated signal. These intense waves occurred at the usual altitudes assoclated with electrojet instabilities for both daytime and nighttime conditions [Fejer and Kelley, 1980], as shown below in the discussion of Fig. 3 .

Model sine waves for the electric field data have been constructed, and the residues (difference between the model and total signal)
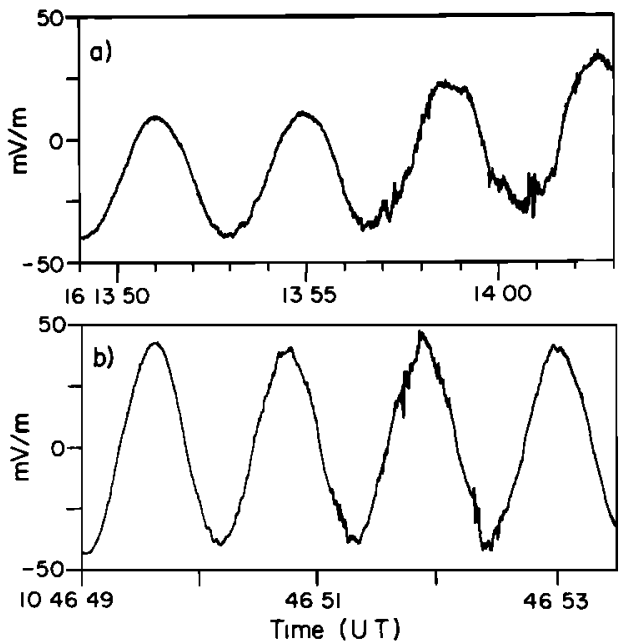

Fig. 1. Raw electric fleld data from (a) daytime (Peru) and (b) nighttime (Kwajalein) flights. 


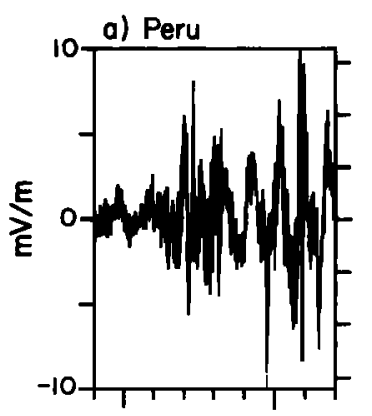

$16: 13 \cdot 55$ b) Kwajalein

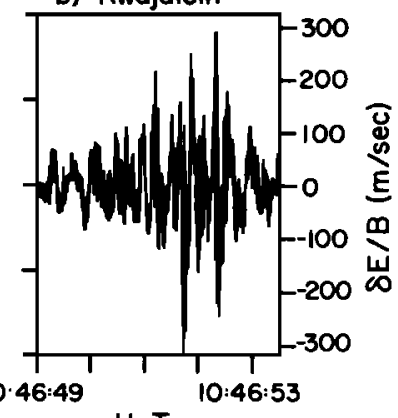

U. T.
F18. 2. Residual (wave fluctuations) from the raw data presented in Figure 1. In each case, the low frequency sine wave due to the ambient and I $\times$ B electric flelds have been subtracted.

are plotted in Fig. 2. Although Invariably some of the longest period perturbed waves were subtracted with the model, the low frequency limit of the residues was chosen $s 0$ as to minimize the contributions related to the spin frequency. Thus, the residues yield an artificial lower limit to the wave fields. In each case, the wave fields were the order of 3 $\mathrm{mV} / \mathrm{m}$ with peak values higher than $5 \mathrm{mV} / \mathrm{m}$. The corresponding electron drift speeds ( $\delta \mathrm{E} / \mathrm{B}$ ) for such fields are 100-165 m/s. Unfortunately, the ambient electrio fleld cannot be determined for either of these data sets, but typical values of the electric field for the two equatorial sites range from 1-10 $\mathrm{mV} / \mathrm{m}$ [Forbes, 1981].

In $F 1 \mathrm{~g} .3 \mathrm{a}$, density data from a swept Langmuir probe on the Peru flight show a typical daytime profile, for which the peak upward directed gradient (e-folding length) is $3.7 \mathrm{~km}$. Plotted alongside is the broadband signal above $34 \mathrm{~Hz}$ from the ac wave recelver as detected in the moving rocket frame. The waves are primar1ly located in the region of upward gradient although they do extend silghtly into the region of near zero gradient. Although not discussed in detall here, the Jicamarca Radar recorded backscatter fluctuations between $114 \mathrm{~km}$ and $91 \mathrm{~km}$, and the electrojet backscatter spectrum detected a mixed type 1/type 2 signature during the flight.

For the nighttime flight, a density profile obtained from a flxed-bias Langmulr probe is plotted in Fig. 3b which shows typical layering in the nighttime electron density [Prakash ot al., 1972]. The three peaks evident in this plot were also present in the upleg data. In this example, the fluctuating electric flelds are seen to correspond to the topside of the lowest layer, and were present in an altitude range of $4 \mathrm{~km}$. The mean value of the inverse gradient scale length in the layer was $1.3 \mathrm{~km}$. Waves were not detected in either of the two upper layers during the downleg although weak fluctuations were seen in the middle layer during the upleg.

Power spectra are presented in Figs. 4 (daytime) and 5 (nighttime). Each electric field spectrum represents a merging of a low frequency spectrum from the de channel with a spectrum from the ac channel (capacitively coupled with a higher gain to extend the dynamic range.) In Fig. 4 the spin modulated sine wave has been left in the data and 1 ts effect is apparent in the spectrum at $0.25 \mathrm{~Hz}$. In Fig. 5a, the spectrum was based on the residual after the model was subtracted. In both cases, the waves due to the electrojet turbulence were greater than the "background" power ascertained from spectra taken prior to entry into the unstable region.

The two spectra are remarkably similar. In both cases the wave induced portion of the spectra are characterized by an interval at low frequencies in which the spectral density maximizes. This is followed by a regime in which the spectral density decreases slowly with increasing frequency, and finally by an interval in which the spectrum decreases rapidly in a nearly power law fashion. The spectral indices deduced from a stralght line fit to a power law from $150-350 \mathrm{~Hz}$ are -3.6 and -3.7 for the Peruvian and Kwajalein data, respectively.

For the Kwajalein flight, we have also made a power spectrum of the data from the fixed blas Langmuir probe, as shown in F1g. 5(b). A similar form is seen in this spectrum as in its electric counterpart, before the density spectrum runs into the nolse around $200 \mathrm{~Hz}$. In particular, the density fluctuation spectrum shows a distinct peak at $3.7 \mathrm{~Hz}$. This spectral peak was well resolved since many cycles were encountered in the layer. When the electric field data from the two spin plane antennae are added to create their vector sum, the power spectrum of the resulting signal shows a single peak (indicated by the dashed Iine) at the same frequency at which the density power spectrum peaks. The double peaks may be explained as an artifact of a spinning directional antenna in the presence of a linearly polarized wave.

The frequency spectrum in the rocket reference
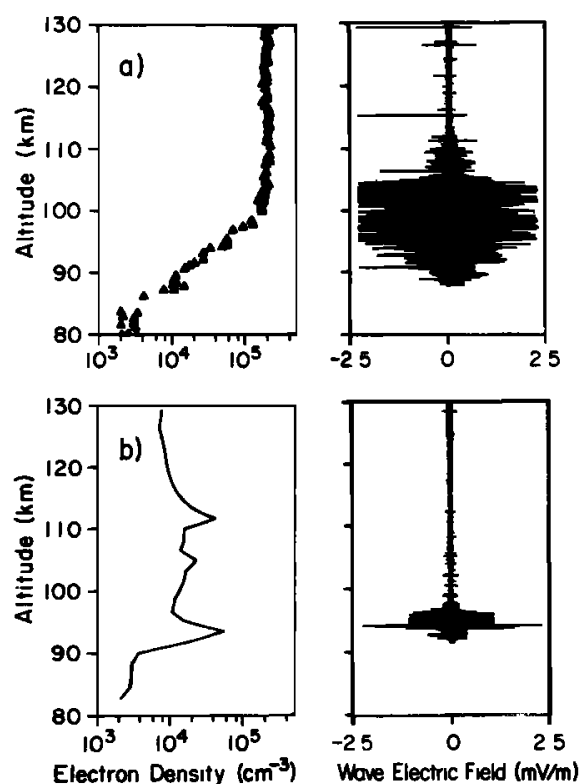

F1g. 3. (a) Electron density data from the swept Langmuir probe together with the high frequency (34-1000 Hz) electric fleld data for the daytime flight. (b) Electron density data (correct to within a factor of 2) from the fixed-bias Langmuir probe on the nighttime flight with the high frequency $(60-1000 \mathrm{~Hz})$ electric field data. 
frame is not particularly useful for comparison with theory. In order to proceed, some assumption must be made to convert to wave number in the plasma frame. As discussed in detall by Fredricks and Coroniti [1976] and by Temerin [1979] this is not a trivial problem, particularly when there is a significant phase velocity (as compared to the rocket velocity) in the plasma frame. In this paper we are primarily interested in comparison between the daytime and nighttime data and in the characteristics of the entire spectrum of electrojet waves. We thus make the usual assumption that the frequency of the waves in the rocket frame is related to the wave number via the Doppler shift $\omega=\underline{k} \cdot \underline{y}$. The wavenumber scale is plotted on the top of the spectra in Figs. 4 and 5 under the assumption that $\underline{k}$ is perpendicular to $B$ and that the $\underline{k}$ values sampled are parallel to the component of velocity in that direction. Since the rocket velocity, $\underline{y}$, was primarily upward while the large amplitude waves discussed in paper 1 appear to have a primarily horizontal phase velocity, their wavelengths would be overestimated using this assumption. It is more likely that the largest wavelength waves measured by the rocket are due to secondary waves generated perpendicular to the direction of the linear instability. At some wavenumber, the turbulence will be isotropic, and our assumption is valid, although it is uncertain at what wavelength this condition is met.

Several points are immediately clear, even though the transformation to wave number is not definitive. As mentioned earlier, the two spectra in Figs. 4 and $5 a$ are similar in form. In both cases most of the energy is located in the longest wavelength portion of the spectrum. This dominant wavelength is not the same in the two data sets, being $1000 \mathrm{~m}$ in Fig. 4 (day) and $350 \mathrm{~m}$ in Fig. 5 (night). Note that the ratio of the zero order density scale lengths driving the two instabilities is approximately the same as the ratio of these two peak wavelengths. The wavelength at which the electric field spectra

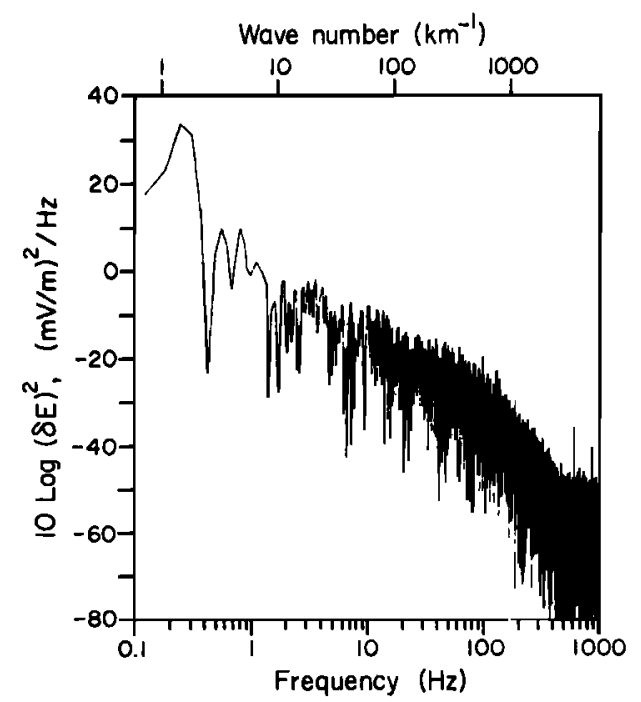

F1g. 4. Power spectrum of the fluctuation electric fields in the daytime (Peru) flight. Note the peak at the spin rate at $0.25 \mathrm{~Hz}$. The data analyzed correspond to +408.0 to +424.4 seconds after launch, or from 116 to $91 \mathrm{~km}$.
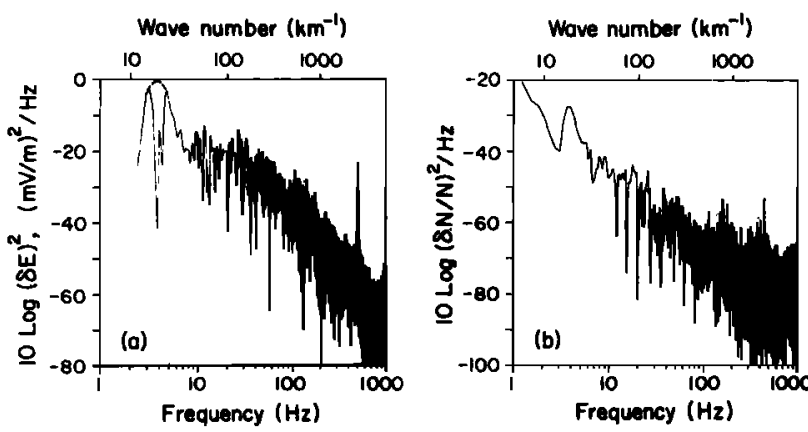

Fig. 5 (a) Power spectrum of the electric fields in the nighttime (Rwajalein) flight. The dashed line corresponds to a peak in the power spectrum of the vector sum of the two spin plane antennae. (b) Power spectrum of density fluctuations simultaneous with the data analyzed in (a). The data were taken from +419.8 to +423.1 seconds after launch, or 98 to $93 \mathrm{~km}$.

break from a slowly decaying spectral density to a steep power law is roughly the same in the two cases, about $30 \mathrm{~m}$. The minimum detectable wavelength in each experiment was about $2 \mathrm{~m}$, but there was no indication that the power law would not continue extending the perturbed wavelengths to even shorter scales.

\section{D1scussion}

The data presented here show perturbation velocities associated with fully developed electrojet instabilities that can be comparable to the driving electron drifts. This result is in agreement with conclusions of radar experimenters and theorists when explaining large Doppler shifts observed Independent of the angle between the radar line of sight and the current [Fejer and Kelley, 1980]. The measured electric flelds are a lower limit to the actual fields present, and Indicate that perturbed vertical electron drifts at least as great as 30-40\% of the sound speed $(400+50 \mathrm{~m} / \mathrm{s}$ at Jicamarca) are generated. The condition that the drift velocity exceed the sound speed, which is necessary for production of short wavelength waves by $a$ secondary two-stream instability [Farley, 1963; Sudan et al., 1973], may conceivably be attained. For the long wavelength approximation, the turbulent electrojet models of sudan et al. [1973] and Balsley and Farley [1973] easily show from the linear theory the relationship between the electric field and density fluctuations as:

$$
\delta E /(\delta N / N) \simeq \nu_{i} \Omega_{i}^{-1}(1+\Psi)^{-1} E_{\text {ambient }}
$$

where $\Psi=\nu_{e} \nu_{i} / \Omega_{i} \Omega_{e}, \nu_{e}$ and $\nu_{i}$ are the electron and ion collision frequencies and $\Omega_{e}$ and $\Omega_{i}$ are the electron and Ion gyro frequencies. The spectral density of the electric field at the peak in Fig. $5 \mathrm{a}$ is $1 \mathrm{mV} / \mathrm{mHz}^{1 / 2}$ while the density spectrum peak value is $0.045 \mathrm{~Hz}^{-1 / 2}$. Using model values for the collision and gyro frequencies, the calculated ambient electric field is thus 1.6 $\mathrm{mV} / \mathrm{m}$. This value is reasonable for the Kwajalein latitude and comparable to $\delta \mathrm{E}$. 
Similarity between the electric fleld spectra imply that the fundamental processes are identical in the two physical situations. During the day the waves were located in a region of positive (upward) density gradient, while at night they were found in a region of negative gradient. Since the vertical electric field is known to reverse sign between daytime and nighttime conditions, this relationship is in good agreement with the Iinear theory of the gradient-drift instability, which requires that the polarization electric field be parallel to the density gradient for wave generation. Plasma density fluctuation measurements made in a series of rocket flights from India displayed a similar relationship between wave occurrence and the density gradient [Prakash et al., 1972]. The data presented here and in paper 1 suggest that a dominant long wave develops with a wavelength the order of the driving gradient scale length. Generation of this dominant wave is thus best described within the context of the gradient-drift theory. Strong evidence supporting this concept stems from the observation that the gradient scale length seems to control the outer scale at least for the vertical wave number spectrum.

The spectral form suggests that positive growth rates exist throughout a range of wavenumbers just above the regime of maximum intensity, where the spectrum is nearly flat. At high wavenumbers, an "inertial subrange" may exist in which energy cascades to smaller scales where it is absorbed as heat in the steady state. The observed spectral slope is consistent with the predictions made by ott and Farley [1974] using dimensional arguments based on an inertial range. Results of numerical simulations by Keskinen et al. [1979] not only agree with the observed spectral slope but also with the observed break in the spectral form at $30 \mathrm{~m}$. However, this does not preclude the possibility that propagating acoustic waves are generated with a power law of this form and contribute to the damping of the larger scale waves. The break in the spectrum occurs at nearly the same wavelength in both data sets. This suggests that the break is controlled by properties of the medium rather than by the free energy source.

In summary, we have studied the electrojet Instability process during both daytime and nighttime conditions using the electric field technique to detect the electrostatic waves. The spectra were measured over three decades of wavelength and six decades of power. Strong evidence exists in paper 1 and to some extent in the present data that the gradient drift process dominates the physics and results in an energy "build-up" in the longest wavelength allowed by the system, a length of the order of the driving gradient. These waves grow to large amplitudes and yield perturbation velocities comparable to the driving drift speed. Secondary waves powered by these large drift speeds very likely create the broad flat portion of the observed spectrum. The secondaries may be either of the two-stream or gradient-drift type.

Acknowledgements. We are indebted to L. Brace of Goddard Space Flight Center for use of the
Langmuir probe data from the Peruvian experiment. We thank $N$. Grossbard of the Alr Force Geophysical Laboratories for his reduction of the D.C. Kwajalein data. R. Pfaff was supported under a grant from the Atmospheric Sclences Division of the National Solence Foundation. Measurements at Kwajalein were supported under Contract DNA001-79-C-0133 at Utah state University. The Peru measurements were taken during "Antarqui", a cooperative space program between IGP and CONIDA of Peru and NASA of the United States.

\section{References}

Agsson, T. L., Probe measurements of electric fields in space, in Atmospherte Emisstions ed. B. M. MeCormac and A. Omholt, 305, Van Nostrand Relnhold (New York), 1969.

Balsley, B. B. and D. T. Farley, Radar observations of two-dimensional turbulence in the equatorial electrojet, I. Geophys. Res., $78,7471,1973$.

Fahleson, U. V., Theory of electric field measurements conducted in the magnetosphere with electric probes, Space Sc1. Rev., I, 238, 1967.

Farley, D. T., A plasma instability resulting in fleld-aligned irregularities in the Ionosphere, J. Geophys. Res., 68, 6083, 1963.

Fejer, B. G. and M. C. Kelley, Ionospheric Irregularities, Rey. Geophy. and Space Phys., $18,401,1980$.

Forbes, J. M., The equatorial electrojet, Rev. Geophys. Space Phys., 19, 469, 1981.

Fredricks, R. W. and F. V. Coroniti, Ambiguities in the deduction of rest frame fluctuation spectrums from spectrums computed in moving frames, J. Geophys. Res., 81, 5591, 1976.

Keskinen, M. J., R. N. Sudan, and R. L. Ferch, Temporal and spatial power spectrum studies of numerical simulations of type 2 gradient drift irregularities in the equatorial electrojet., J. Geophys. Res., 84, 1419, 1979.

Kudek1, E., D. T. Farley, and B. G. Fejer, Long wavelength irregularities in the equatorial electrojet, Geophys. Res. Lett., this issue, 1982.

Ott, E. and D. T. Farley, The k-spectrum of Ionospheric Irregularities, J. Geophys. Res., 79, 2469, 1974 .

Prakash, S., B. H. Subbaraya, and S. P. Gupta, Rocket measurements of lonization irregularities in the equatorial ionosphere at Thumba and identification of plasma irregularities, Indian I. Radio Space Phys., 1, 72, 1972.

Sudan, R. N., J. Akinrimisi, and D. T. Farley, Generation of small-scale irregularities in the equatorial electrojet, I. Geophrs. Res., $78,240,1973$.

Temerin, M., Doppler shift effects on double-probe-measured electric field power spectra, I. Geophys. Res., 84, 5929, 1979. 